\title{
Effect of Micro Injection Molding Parameters on Cavity Pressure and Temperature Assisted by Taguchi Method
}

\author{
Quan WANG*, Chongying YANG**, Kaihui DU***, Zhenghuan WU**** \\ *National Local Joint Engineering Laboratory of Intelligent Manufacturing Oriented Automobile Die\& Mold, \\ Tianjin University of Technology and Education, Tianjin, 300222, China, E-mail: wq2001126@163.com \\ **College of mechanical engineering, Tianjin University of Technology and Education, Tianjin, 300222, China, \\ E-mail: yangcy521@163.com \\ ***College of mechanical engineering, Tianjin University of Technology and Education, Tianjin, 300222, China, \\ E-mail: 360066439@qq.com \\ ****College of mechanical engineering, Tianjin University of Technology and Education, Tianjin, 300222, China, \\ E-mail:wzh46817@163.com
}

cross $^{\text {ref }}$ http://dx.doi.org/10.5755/j01.mech.25.4.20999

\section{Introduction}

Injection molding technology has been used for more than 100 years. However, the production of micro- and Nano-parts by this method is still new $[1,2]$. Current research is focused on applying this technology to the fabrication of small, affordable parts, instead of using expensive conventional techniques. Micro- and Nano-scale injection moldings of small complex parts are mainly used in electronic and micro-electromechanical systems and biological applications [3, 4]. Micro-injection molding is utilized with micro-weights parts; that is, the weight of the parts is on the order of a few milligrams, but the dimensions are not on a micron scale. This technique also involves parts with microstructured regions (e.g., micro-slots, micro-holes) and parts with micro-precision dimensions. Thus, such products require a micron-range tolerance [5].

Increased demand for micro-scale parts and devices are being met in many cases by micro-injection molding of polymer parts. However, part inspection is difficult due to the micro-scale dimension in the micro-injection molding process. In addition, process control also becomes challenging since the process is susceptible to slight changes in process parameters such as mold temperature, injection velocity, and packing pressure etc. [6-8]. To address these issues, a suitable process monitoring method such as cavity pressure monitoring can be employed to detect any process deviation that may cause defects in part quality. Cavity pressure has been found to be a reliable process indicator in injection molding for both part quality and process monitoring. Specifically, it has been found to provide real-time detection of part and process deviation [9-13]. As such, cavity pressure measurement holds potential for monitoring part quality in micro-injection molding where direct part inspection is difficult and often costly due to part handling issues and microscopic feature sizes.

Although the processing window for micro-injection molding was smaller than macro-molding, the cavity pressure and temperature curves were able to capture the differences in molding conditions. Furthermore, attributes obtained from the pressure curve such as peak cavity pressure was found to have good correlation with part weight which was used as the quality metric [14]. In terms of defects among the parts, peak cavity pressure was able to de- tect defective parts based on the measured peak cavity pressure value. The finding from the current investigation demonstrates significant potential for cavity pressure to be utilized as an indicator of part quality as well as a process monitoring tool for the microinjection molding process [1519]. Moreover, effect of injection molding parameters of injection molded polymer materials on the cavity pressure is less been reported.

In order to investigate the mechanism of micro injection molding parameters on cavity pressure and temperature, the diverse spline was conducted using polypropylene under varying processing parameters to observe how cavity pressure and temperature responded to the different molding conditions in this paper. The final part of the investigation involved using the orthogonal design approach to include a broader range of processing parameters.

\section{Taguchi design}

In the process of injection molding, parameters in injection process can significantly influence the quality of injection-molded parts. Therefore in actual productions, a number of test factors need to be investigated simultaneously. However, overall test is difficult to be carried out due to large test scales and limits of test costs. Orthogonal design is a high-efficiency design method for tests to arrange multifactor tests and seek optimal level combinations. The design method of orthogonal tests is able to determine optimal parameters by simply calculating influences of each factor on test results, showing the influences in charts, and then comprehensively comparing differences. The calculation is carried out on orthogonal tables, so the whole process is simple and clear. In this way, enough information can be obtained through a few tests, thus saving costs. The parameters used for the cavity pressure and temperature were the melt temperature $(A)$, mold temperature $(B)$, packing pressure $(C)$, packing time $(D)$ and injection pressure $(E)$. The values of these parameters are presented in Table 1 .

\subsection{Taguchi design of tensile specimen}

An $L_{16}\left(4^{5}\right)$ orthogonal array was selected for the experimental design for each of the five factors. The four levels for the five parameters were identified during the 16 experiments. The values of these parameters are presented 
in Table 2. The experiments were carried on micro injection molding machine. The real-time curves of data were output, and the average value of maximum tensile spline of cavity pressure were obtained.

Table 1

Process parameters and their levels

\begin{tabular}{|c|c|c|c|c|c|}
\hline \multirow{3}{*}{ Factor } & $A$ & $B$ & $C$ & $D$ & $E$ \\
\cline { 2 - 6 } & $\begin{array}{c}\text { Melt temperature, } \\
{ }^{\circ} \mathrm{C}\end{array}$ & $\begin{array}{c}\text { Mold temperature, } \\
{ }^{\circ} \mathrm{C}\end{array}$ & $\begin{array}{c}\text { Packing pressure, } \\
\text { MPa }\end{array}$ & Packing time, s & $\begin{array}{c}\text { Injection pressure, } \\
\mathrm{MPa}\end{array}$ \\
\hline 1 & 220 & 40 & 85 & 5 & 85 \\
\hline 2 & 230 & 50 & 90 & 10 & 90 \\
\hline 3 & 240 & 60 & 95 & 15 & 95 \\
\hline 4 & 250 & 70 & 100 & 20 & 100 \\
\hline
\end{tabular}

Proposed $L_{16}\left(4^{5}\right)$ orthogonal array of tensile specimen

\begin{tabular}{|c|c|c|c|c|c|c|}
\hline Run & $A,{ }^{\circ} \mathrm{C}$ & $B,{ }^{\circ} \mathrm{C}$ & $C, \mathrm{MPa}$ & $D, \mathrm{~s}$ & $E, \mathrm{MPa}$ & Max average value/bar \\
\hline 1 & 220 & 40 & 85 & 5 & 85 & 395.08 \\
\hline 2 & 220 & 50 & 90 & 10 & 90 & 473.91 \\
\hline 3 & 220 & 60 & 95 & 15 & 95 & 524.11 \\
\hline 4 & 220 & 70 & 100 & 20 & 100 & 591.79 \\
\hline 5 & 230 & 40 & 90 & 15 & 100 & 486.71 \\
\hline 6 & 230 & 50 & 85 & 20 & 95 & 604.38 \\
\hline 7 & 230 & 60 & 100 & 5 & 90 & 608.54 \\
\hline 8 & 230 & 70 & 95 & 10 & 85 & 543.94 \\
\hline 9 & 240 & 40 & 95 & 20 & 90 & 628.34 \\
\hline 10 & 240 & 50 & 100 & 15 & 85 & 498.69 \\
\hline 11 & 240 & 60 & 85 & 10 & 100 & 556.84 \\
\hline 12 & 240 & 70 & 90 & 5 & 95 & 626.20 \\
\hline 13 & 250 & 40 & 100 & 10 & 95 & 609.91 \\
\hline 14 & 250 & 50 & 95 & 5 & 100 & 541.86 \\
\hline 15 & 250 & 60 & 90 & 20 & 85 & 523.21 \\
\hline 16 & 250 & 70 & 85 & 15 & 90 & \\
\hline$K_{1}$ & 496.222 & 512.983 & 467.840 & 541.607 & 543.455 & \\
\hline$K_{2}$ & 538.558 & 541.635 & 514.830 & 551.835 & 536.415 & \\
\hline$K_{3}$ & 556.953 & 542.315 & 571.625 & 540.592 & 540.382 & \\
\hline$K_{4}$ & 575.295 & 570.095 & 612.733 & 532.993 & 546.775 & \\
\hline$R$ & 79.073 & 57.112 & 144.893 & 18.842 & 10.360 & \\
\hline$K_{2}, K_{3}$ & 15 & & & & \\
\hline
\end{tabular}

$K_{1}, K_{2}, K_{3}, K_{4}$ is variance, $R$ is range

Based on the experimental results of Table 2, the range $R$ value is greater and the impact of the factors is greater on the test index. For the tensile spline, the order of the injection molding process parameters on the maximum value of the cavity pressure is: $C$ (packing pressure) $>A$ (melt temperature) $>B$ (mold temperature) $>D$ (packing time) $>E$ (injection pressure).

To further analyse the variance of the results, the influence of the process parameters on the maximum value of mold cavity pressure can be analysed. It can be seen from the Table 3, the influence of packing pressure on the mold cavity pressure is larger. According to $\mathrm{F}$ value, the pressure of the mold cavity pressure has significant influence on the cavity pressure. The melt temperature, mold temperature, packing pressure time and injection pressure to the mold cavity pressure maximum influence is smaller.

Table 3

Variance analysis of tensile specimen

\begin{tabular}{|c|c|c|c|c|c|}
\hline Factor & Square of deviance & DoF & Variance & Average variance & Significant \\
\hline$A$ & 13757.313 & 3 & 4585.771 & 0.987 & \\
\hline$B$ & 6524.361 & 3 & 2174.787 & 0.468 & \\
\hline$C$ & 48473.621 & 3 & 16157.874 & 3.477 & $*$ \\
\hline$D$ & 719.044 & 3 & 239.681 & 0.052 & \\
\hline$E$ & 233.959 & 3 & 77.986 & 0.017 & \\
\hline
\end{tabular}

\subsection{Taguchi design of impact specimen}

The average value of the pressure of the impact sample is shown in Table 4. According to the analysis of the experimental results in Table 4, can be seen for the impact spline, the effect order of injection molding process parameters on the maximum cavity pressure is as follows: $C$ (packing pressure) $>A$ (melt temperature) $>B$ (mold temperature) $>D$ (packing time) $>E$ (injection pressure) . 
Table 4

Proposed $L_{16}\left(4^{5}\right)$ orthogonal array of impact specimen

\begin{tabular}{|c|c|c|c|c|c|c|}
\hline Run & $A$ & $B$ & $C$ & $D$ & $E$ & Max average value/bar \\
\hline 1 & 220 & 40 & 85 & 5 & 85 & 421.71 \\
\hline 2 & 220 & 50 & 90 & 10 & 90 & 501.08 \\
\hline 3 & 220 & 60 & 95 & 15 & 95 & 552.35 \\
\hline 4 & 220 & 70 & 100 & 20 & 100 & 621.90 \\
\hline 5 & 230 & 40 & 90 & 15 & 100 & 511.75 \\
\hline 6 & 230 & 50 & 85 & 20 & 95 & 476.90 \\
\hline 7 & 230 & 60 & 100 & 5 & 90 & 635.52 \\
\hline 8 & 230 & 70 & 95 & 10 & 85 & 640.76 \\
\hline 9 & 240 & 40 & 95 & 20 & 90 & 571.25 \\
\hline 10 & 240 & 50 & 100 & 15 & 85 & 662.17 \\
\hline 11 & 240 & 60 & 85 & 10 & 100 & 523.71 \\
\hline 12 & 240 & 70 & 90 & 5 & 95 & 585.18 \\
\hline 13 & 250 & 40 & 100 & 10 & 95 & 659.74 \\
\hline 14 & 250 & 50 & 95 & 5 & 100 & 642.40 \\
\hline 15 & 250 & 60 & 90 & 20 & 85 & 572.51 \\
\hline 16 & 250 & 70 & 85 & 15 & 90 & 548.88 \\
\hline$K_{1}$ & 524.260 & 541.112 & 492.800 & 571.202 & 574.287 & \\
\hline$K_{2}$ & 566.233 & 570.638 & 542.630 & 581.322 & 564.183 & \\
\hline$K_{3}$ & 585.577 & 571.023 & 601.690 & 568.788 & 568.543 & \\
\hline $\mathrm{K}_{4}$ & 605.883 & 599.180 & 644.832 & 560.640 & 574.940 & \\
\hline$R$ & 81.621 & 58.068 & 152.032 & 20.682 & 10.757 & \\
\hline
\end{tabular}

Further variance analysis was carried out on the above results, and the influence of process parameters on the maximum value of mold cavity pressure was analysed. As can be seen from the Table 5, the factor $C$ (packing pressure) is 3.516, which shows that the influence of packing pressure of the mold cavity pressure is significant.

Table 5

Variance analysis of impact specimen

\begin{tabular}{|c|c|c|c|c|c|}
\hline Factor & Square of deviance & DoF & Variance & Average variance & Significant \\
\hline$A$ & 14542.404 & 3 & 4847.468 & 0.960 & \\
\hline$B$ & 6745.836 & 3 & 2248.612 & 0.445 & \\
\hline$C$ & 53248.652 & 3 & 17749.551 & 3.516 & $*$ \\
\hline$D$ & 871.087 & 3 & 290.362 & 0.058 & \\
\hline$E$ & 311.203 & 3 & 103.734 & 0.021 & \\
\hline
\end{tabular}

\section{Experimental}

Materials: The sample material used in this work was polypropylene in the form of pellets and with a trade mark 5090T (MFI=15g/10min), supplied by the Formosa petrochemical Corp, Taiwan.

Mold: The multi-spline injection mold constructed from two parts (tensile specimen and impact specimen) shown in Fig. 1. The mold cavity of thicknesses is $1 \mathrm{~mm}$. Fig. 2 shows the product produced by the injection molding and the cavity pressure is measured at the back of the part.

Injection molding machine: The experimental work was carried out on an injection molding machine of type BOX XS concept having a maximum injection pressure 2298 bar, with screw diameter for plastication $14 \mathrm{~mm}$ and maximum weight of the product $6.1 \mathrm{~g}$.

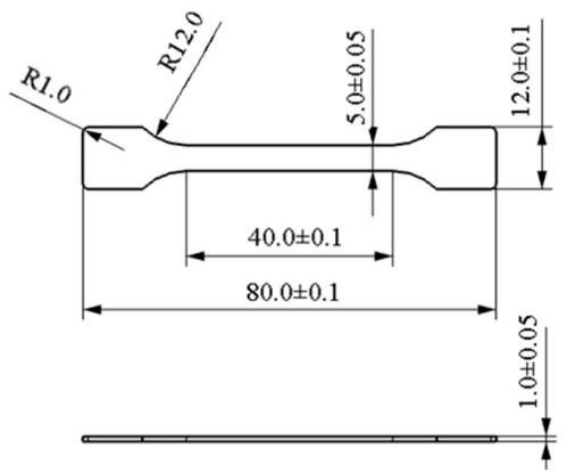

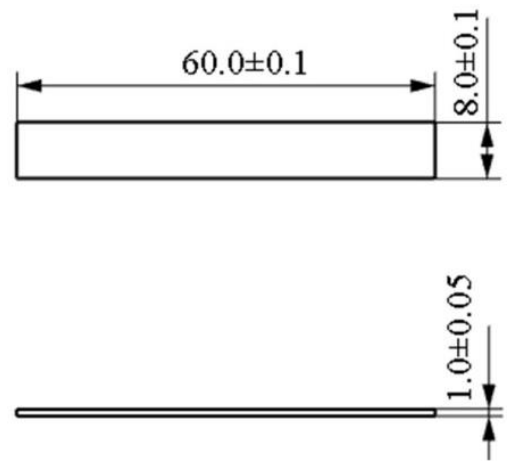

Fig. 1 Geometry and dimensions of the tensile and impact specimen 
Amplifier (type Kistler 1708B0): It is used to convert the electrical charge of the pressure sensor signals yielded by piezoelectric into proportional voltages. The output of the amplifier is transferred to the center of acquisition system and another output is transferred to a universal indicator. The output signals from the amplifier are 0-10 DC voltages which are transmitted to the recorder and the data acquisition system.

Acquisition data: Data output from the amplifier is collected using a Kistler 5865 Como injection system. Computer is used to record the output reading of the acquisition system through an interface cart by the help of lab view program.

Kistler 6190CA: The cavity pressure and temperature is measured in the mold cavity by the quartz sensor for mold cavity pressure type Kistler 6190CA, which has a front of $4.0 \mathrm{~mm}$ diameter. The pressure transducer has a sensibility of 2.5 bar and it is able to register changes of the pressure as a function of time with the resolution up to $0.01 \mathrm{~s}$. The pressure acting directly on the entire front of the sensor is transferred to the quartz measuring element, which produces an electrical charge proportional to the pressure.
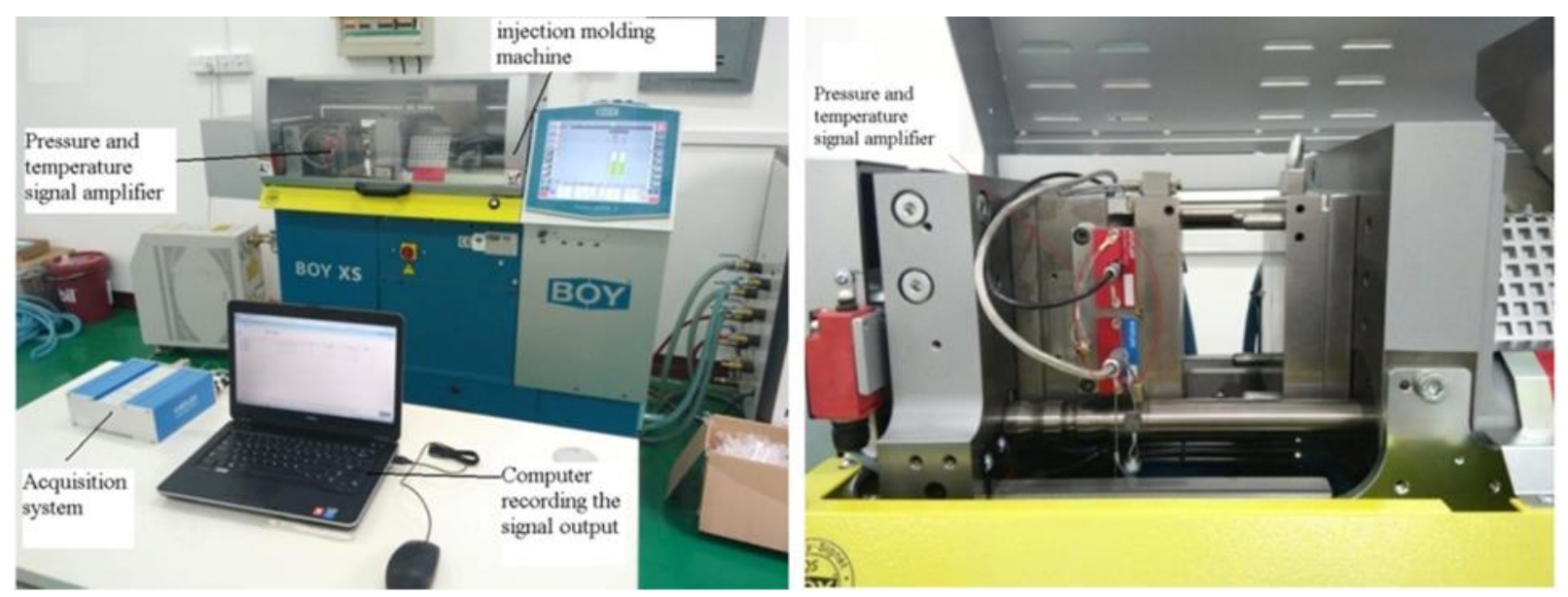

Fig. 3 Experimental equipment of injection molding

The polymer material inside the hopper passes to the plasticization cylinder where it is melted to the injection temperature and injected to the mold cavity through the runner and gate. The hot plastic material injected inside the cavity is cooled by cooling water circulating through four cooling channels inside the fixed and movable parts. At the end of the cooling stage, the product is ejected out of the machine to start a new cycle. The real-time data acquisition of cavity pressure and temperature are shown is Fig. 4. During the experimental work and for each case studied, the following procedures are performed:

1. Adjust the cooling water inlet to have the same inlet temperature and flow rate for all cases.

2. Adjust the process parameters (melt temperature, packing time, injection pressure, etc.) of the injection molding machine by the machine regulator to suit each studied case and wait until reaching steady-state values especially for inlet polymer temperature before starting the injection molding cycle.

3. Wait sufficient time until all the thermocouple readings by the recorder have the same values to ensure that the mold temperature is initially at the same temperature of water inlet.

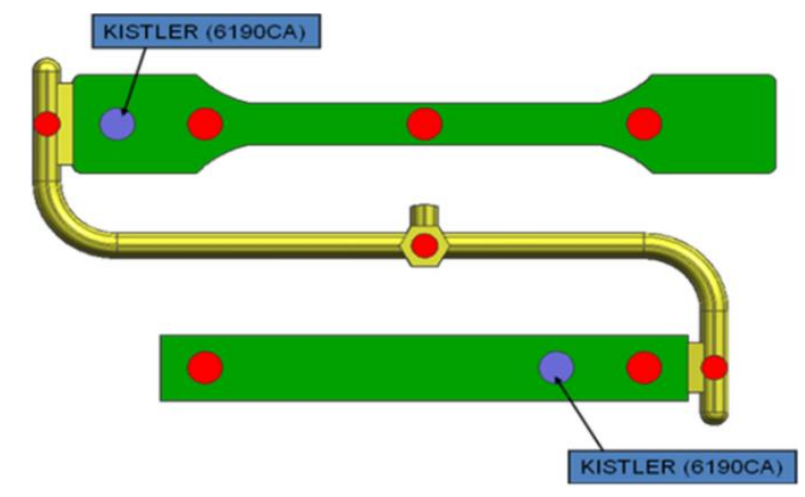

Fig. 2 Locations of sensors in the mold

Mold temperature controller: The mold temperature controller (model TP6ZE) was adopted using PIOVAN Co. Ltd, Italia.

Chiller: Chiller (model ML-CA03) was adopted using Ming Lee Co. Ltd, Hong kong, China.

The experimental equipment of micro injection molding for measuring cavity pressure and temperature is shown in Fig. 3.

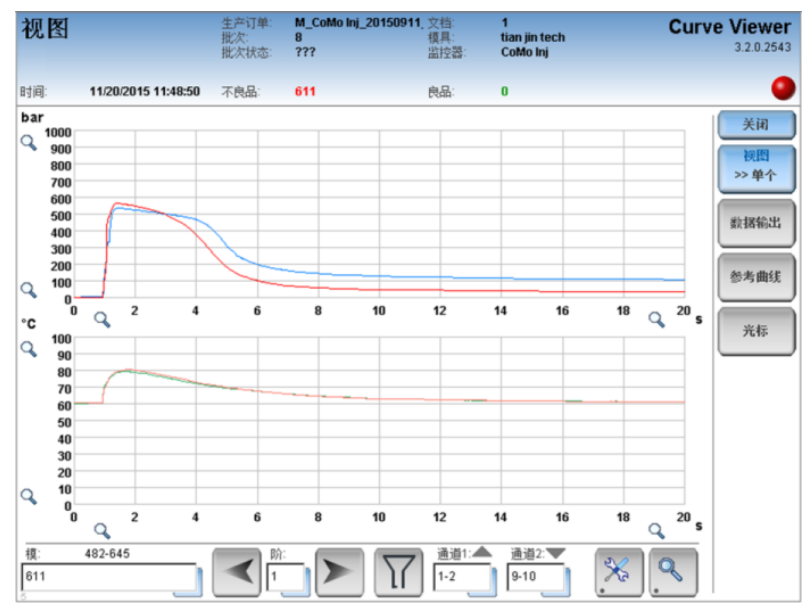

Fig. 4 Real-time data acquisition

4. Run the acquisition data system for reading all of the input values (mold temperature, inlet temperature of cooling water flow rate, and cavity pressure).

5. Run the lab view program through the computer to record the output data from the acquisition data system in a separate file inside the computer. 
6. Run the injection molding machine to start mold cycles until finishing the required cycles for each case studied.

7. During all case studied, verifying that the values of the flow rate and inlet water temperature are constant during each experimental case by verifying their value through the indicator.

8. Wait until the reading of all thermocouple gives the same reading of the initial value of the inlet water temperature. another case.

9. Repeating the same previous procedures to start

\section{Results and discussion}

The parameters of injection molding process have different influences on the maximum cavity pressures and temperature of multi-spline samples. Fig. 5 show the curve relationship between melt temperature and the maximum cavity pressure and temperature in a double-cavity mold. In the Fig. 5, the maximum cavity pressure of tensile and impact pressures dramatically and then slowly increases with melt temperature. When the melt temperature is low, high filling cavity pressures and shear stresses in cavities result in the rapid increase of pressures. With the rise of temperature of plastic melts, the viscosity of polymer decreases continuously and the pouring gates coagulate slowly. In addition, it needs a long time to fill materials during which little pressure is lost, thereby increasing the maximum cavity pressure. With same injection processing parameters, the average value of the maximum cavity pressure of impact samples is larger than that of tensile samples. It is obvious that the pressures of cavities in the two types of samples are different in the injection. The injection processing parameters exert dissimilar effects on cavity temperature. With same injection processing parameters, the average value of the maximum cavity temperature of impact samples is higher than that of tensile samples. The maximum cavity temperature continuously increases with melt temperature. The direct-contact pressure-temperature sensor used in the test is directly contacted with plastic melts, the increase of melt temperature can affect the temperature measured by the sensor. Therefore, the maximum cavity temperature measured by the sensor rises correspondingly.

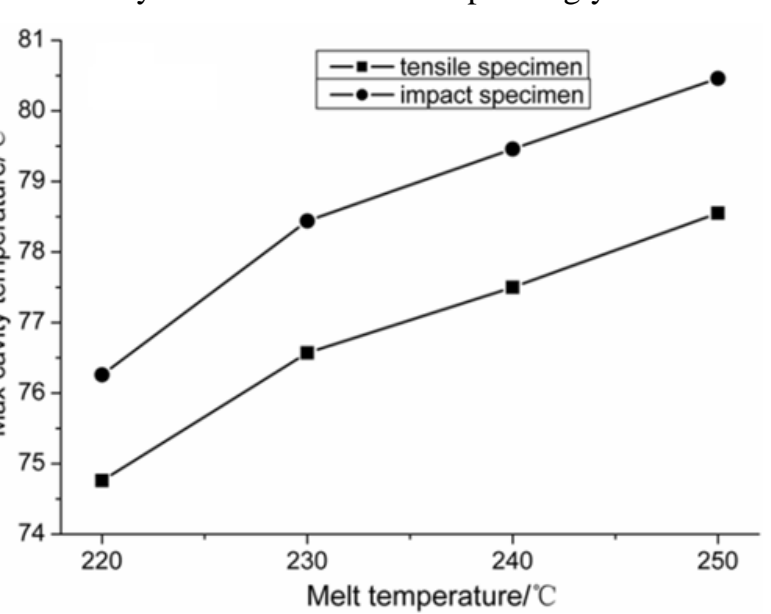

Fig. 5 Relationship between melt temperature and the maximum cavity pressure and temperature

Fig. 6 demonstrate the curve relationship between mold temperature and the maximum cavity pressure and temperature. It can be seen from the figure that the two curves increase first and stabilize, and then increase constantly. The higher the mold temperature, the more easily the melt enter into cavities of molds, thus improving the fluidity of melts in cavities and reducing pressure losses. In addition, in the stage of packing pressures, the increase of mold temperature makes it easy for melts to enter into cavities and decreases pressure losses. This is the reason why the maximum cavity pressure constantly increases with the rise of mold temperature. With the constant increase of mold temperature, the maximum cavity temperature rises correspondingly in an approximately linear manner with a small difference. Due to the efficiency of the mold temperature controller directly acts on mold cores, after setting values on the mold temperature controller, the efficiency is also directly reflected by cavity temperature measured by the sensor. In conclusion, mold temperature is a significant parameter for the maximum cavity temperature.

The curve relationship between packing pressures and the maximum cavity pressure and temperature is shown in Fig. 7. With the constant increase of packing pressures, the maximum cavity pressure also rises, almost showing linear relationship. If the packing pressure is low, it fails to overcome the resistances of pouring gates, resulting in low cavity pressures. So, increasing packing pressures can overcome the resistances of pouring gates and plastic melts can smoothly enter into cavities for feeding, thereby raising the maximum cavity pressure. Packing pressure significantly influences the maximum cavity pressure. The maximum cavity temperature of tensile samples slowly increases all the time, while that of impact samples slightly fluctuates in the beginning and then increases dramatically. The reason is that in the stage of packing pressures, if the packing pressures are small, plastic melts are hard to enter into cavities and cannot compensate temperature losses. If the packing pressures are too large, supplementary melts can enter into cavities, thus compensating temperature losses and raising the maximum cavity temperature.

The curve relationship between packing time and the maximum cavity pressure and temperature in a doublecavity mold is displayed in Fig. 8. The pressure curves of two cavities are similar. With prolonging packing time, the maximum cavity pressure increases firstly and then decrease after reaching to a certain value. If the packing time is too long, melts in cavities have been coagulated while pouring 
gates are not coagulated, so the maximum value of the whole cavity pressure reduces. The values of maximum cavity temperature of the two samples constantly decline with packing time. Because packing time is prolonged, plastic melts in cavities are coagulated, thereby reducing the temperature in cavities.
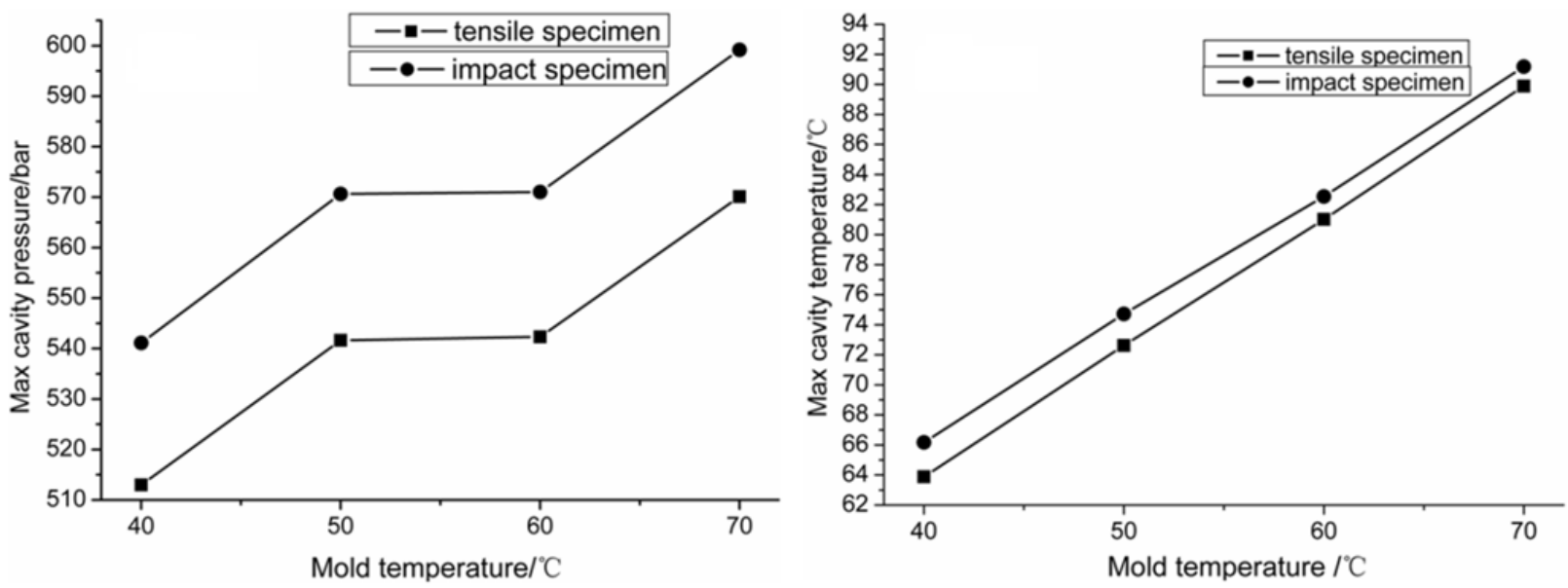

Fig. 6 Relationship between mold temperature and the maximum cavity pressure and temperature
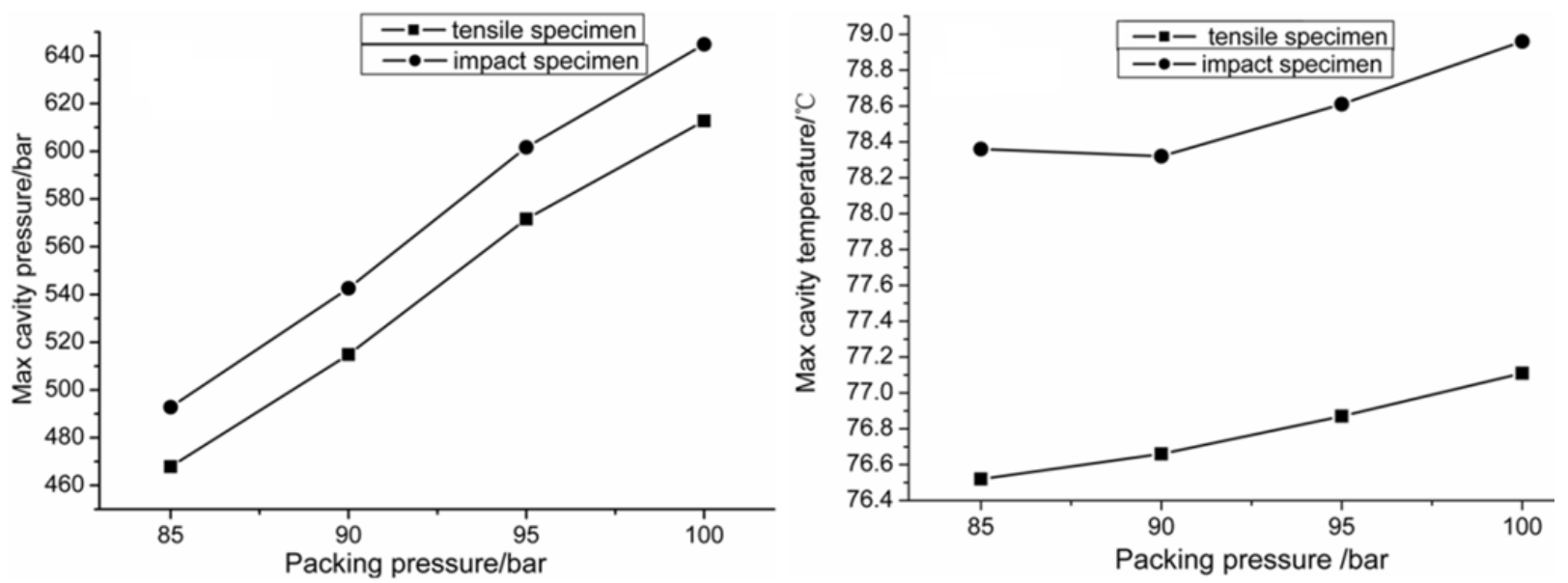

Fig. 7 Relationship between packing pressure and the maximum cavity pressure and temperature
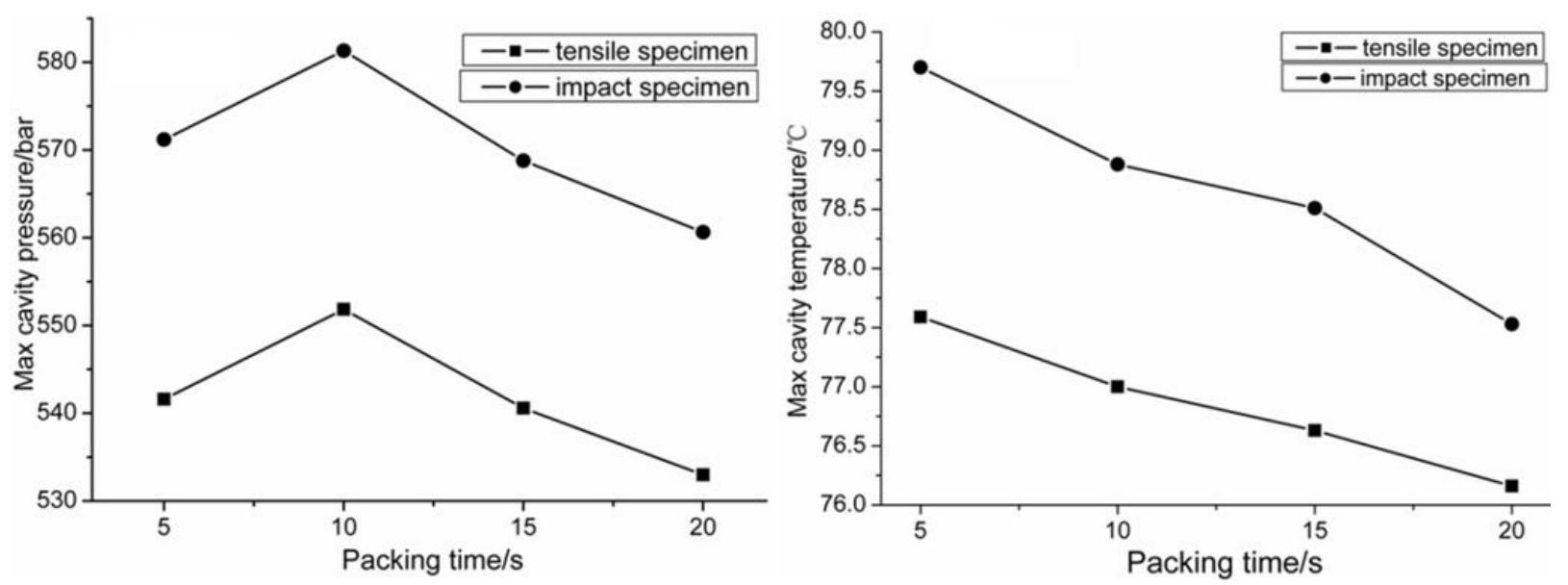

Fig. 8 Relationship between packing time and the maximum cavity pressure and temperature

Fig. 9 displays curve relationship between injection pressures and the maximum cavity pressure and temperature. The two curves are similar and with the increase of injection pressures, the two maximum cavity pressures firstly decrease and then increase constantly. When the injection pressures increase, although the maximum cavity temperature of tensile and impact samples fluctuates, the changes are small, being within $1^{\circ} \mathrm{C}$. Therefore, injection pressures slightly affect the maximum cavity temperature of multiple samples.

Through above analysis, it can be seen that in the same injection process, the maximum cavity pressure of impact samples is larger than that of tensile samples. This is because the two samples have different lengths and it needs a shorter time for impact samples to fill cavities. After filling, tensile samples do not completely fill the cavities. Furthermore, over packing pressures appear due to excessive melts entering into impact samples. Therefore, compared 
with tensile samples, impact samples have larger maximum cavity pressure. The maximum cavity temperature of impact samples is larger than that of tensile samples because of different lengths. When impact samples fill cavities, tensile

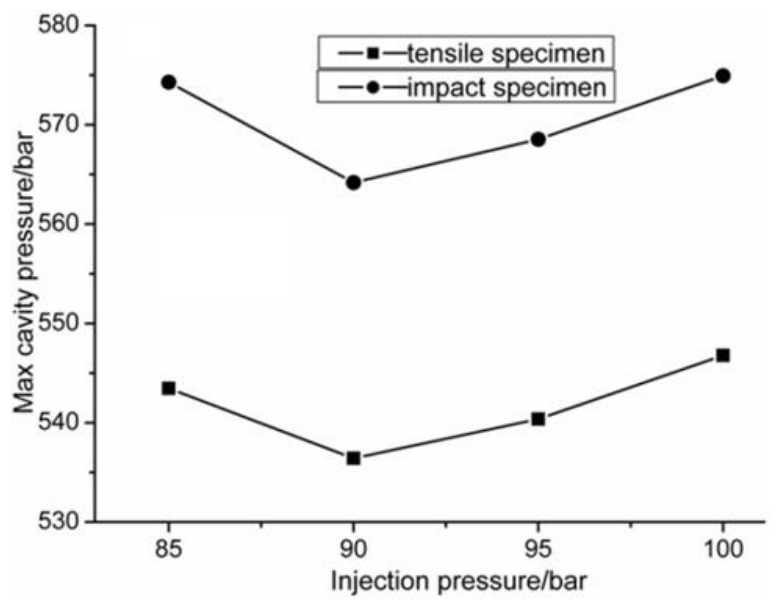

samples do not finish the filling. Meanwhile, too many melts enter into impact samples so little temperature is lost. Therefore, impact samples have higher maximum cavity temperature.

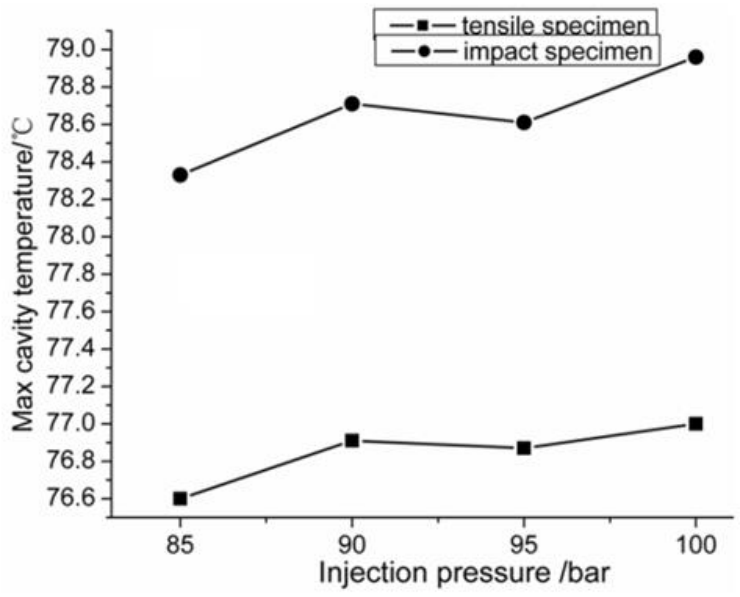

Fig. 9 Relationship between injection pressure and the maximum cavity pressure and temperature

\section{Conclusions}

An experimental work is carried out to study the effect of the injection molding parameters on the cavity pressure and temperature. The results indicate that the characteristics of curve of cavity pressures at different mold parts can be directly revealed and the differences of cavity pressure curve in symmetrical parts are accurately reflected by employing cavity pressure sensors. Furthermore, it reflects different changes of plastic melts in cavities. For tensile and impact samples, the influences of injection processing parameters on the maximum cavity pressures are in a decreasing order as packing pressure, melt temperature, mold temperature, packing time, and injection pressure. Packing pressure most significantly affects the maximum cavity pressure. For tensile and impact samples, the influences of processing parameters on the maximum cavity temperature are listed in a descending order as mold temperature, melt temperature, packing time, packing pressure, and injection pressure. Therefore, mold temperature has the most significant influences on the maximum cavity temperature. The results obtained illustrate well the evolution of the cavity pressure and temperature inside the mold cavity for different process parameters of the injection molding.

\section{References}

1. Tsai, K. M.; Luo, H. J. 2015. Comparison of injection molding process windows for plastic lens established by artificial neural network and response surface methodolog, International Journal of Advanced Manufacturing Technology 77(9): 1599-1611. https://doi.org/10.1007/s00170-014-6366-6.

2. Zamani, H.; Azmoudeh, S; Shelesh-Nezhad, K. 2014.Warpage characterization of thin and centrally-gated injection molded part by applying cavity pressure measurement, Applied Mechanical Material 446:10991103.

https://doi.org/10.4028/www.scientific.net/AMM.446447.1099.

3. Kim, M. M.; Gang, M. G.; Min, B. K.; Kim, W. B. 2014. Experimental and numerical investigations of cavity filling process in injection moulding for microcantilever structures, International Journal of Advanced Manufacturing Technology 75(1):293-304. https://doi.org/10.1007/s00170-014-6104-0.

4. Gordon, G.; Kazmer, D. O.; Tang, X. Y.; Fan, Z. Y.; Gao, R. X. 2015. Quality control using a multivariate injection molding sensor, International Journal of Advanced Manufacturing Technology 78(9):1381-1391. https://doi.org/10.1007/s00170-014-6706-6.

5. Kurt, M.; Kamber, O. S.; Kaynak, Y.; Atakok, G.; Girit, O. 2009. Experimental investigation of plastic injection molding: Assessment of the effects of cavity pressure and mold temperature on the quality of the final products, Materials \& Design 30(8):3217-3224. https://doi.org/10.1016/j.matdes.2009.01.004.

6. Hakimian, E.; Sulong, A. B. 2012.Analysis of warpage and shrinkage properties of injection-molded micro gears polymer composites using numerical simulations assisted by the Taguchi method, Materials \& Design 42(1):62-71.

https://doi.org/10.1016/j.matdes.2012.04.058.

7. Nguyen-Chung, T.; Loeser, C.; Juettner, G.; Pham, T.; Obadal, M.; Gehde, M. 2011. Simulation of the micro-injection moulding process: effect of the thermorheological status on the morphology, Journal of Process Mechanical Engineering 225(4):224-238. https://doi.org/10.1177/0954408911415940.

8. Hassan, H.; Regnier, N.; Le Bot, C.; Defaye, G. 2010. 3D study of cooling system effect on the heat transfer during polymer injection molding, International Journal of Thermal Sciences 49(1):161-169. https://doi.org/10.1016/j.ijthermalsci.2009.07.006.

9. Yang, C.; Li, L.; Huang, H. X; Castro, J. M.; Yi, A. Y. 2010.Replication characterization of microribs fabricated by combining ultraprecision machining and microinjection molding, Polymer Engineering and Science 5(10):2021-2030. https://doi.org/10.1002/pen.21730.

10. Tsai, K. M.; Hsieh, C. Y.; Lo, W. C. 2009. A study of the effects of process parameters for injection molding on surface quality of optical lenses, Journal of Materials Processing Technology 209(7):3469-3477. 
https://doi.org/10.1016/j.jmatprotec.2008.08.006.

11. Le, M. C.; Belhabib, S.; Nicolazo, C.; Vachot, P.; Mousseau, P.; Sarda, A.; Deterre, R. 2011. Pressure influence on crystallization kinetics during injection molding, Journal of Materials Processing Technology 211(11):1757-1763. https://doi.org/10.1016/j.jmatprotec.2011.05.017.

12. Urwyler, P.; Schift, H.; Gobrecht, J.; Hafeli, O.; Altana, M.; Battiston, F.; Muller, B. 2011.Surface patterned polymer micro-cantilever arrays for sensing, Sensors and Actuators A-Physical 172(1):2-8. https://doi.org/10.1016/j.sna.2010.12.007.

13. Nguyen, Q. M. P.; Chen, X.; Lam, Y. C.; Yue, C. Y. 2011. Effects of polymer melt compressibility on mold filling in micro-injection molding, Journal of Micromechanics and Microengineering 21(9):95-109. https://doi.org/10.1088/0960-1317/21/9/095019.

14. Hassan, H. 2013. An experimental work on the effect of injection molding parameters on the cavity pressure and product weight, International Journal of Advanced Manufacturing Technology 67(1):675-686. https://doi.org/10.1007/s00170-012-4514-4.

15. Bellantone, V.; Surace, R.; Trotta, G.; Fassi, I. 2013. Replication capability of micro injection moulding process for polymeric parts manufacturing, International Journal of Advanced Manufacturing Technology 67(5):1407-1421.

https://doi.org/10.1007/s00170-012-4577-2.

16. Tosello, G.; Gava, A.; Hansen, H. N.; Luccetta, G. 2010. Study of process parameters effect on the filling phase of micro-injection moulding using weld lines as flow markers, International Journal of Advanced Manufacturing Technology 47(1):81-97. https://doi.org/10.1007/s00170-009-2100-1.

17. Lin, Y.; Chang, C. H.; Young, W. B. 2010. Experimental and analytical study on filling of nano structures in micro injection molding, International Communications in Heat and Mass Transfer 37(10):1477-1486.

https://doi.org/10.1016/j.icheatmasstransfer.2010.08.017.

18. Kuhn, S.; Burr, A.; Kubler, M.; Deckert, M.; Bleesen, C. 2010. Study on the replication quality of micro-structures in the injection molding process with dynamical tool tempering systems, Microsystem Technologies 16(10):1787-1801. https://doi.org/10.1007/s00542-010-1104-y.

19. Nguyen-Chung, T.; Juettner, G.; Loeser, C.; Pham, T.; Gehde, M. 2010. Determination of the heat transfer coefficient from short-shots studies and precise simulation of microinjection molding, Polymer Engineering and Science 50(1):165-173.

https://doi.org/10.1002/pen.21536.
Q. Wang, Ch. Yang, K. Du, Zh. Wu

\section{EFFECT OF MICRO INJECTION MOLDING PARAMETERS ON CACITY PRESSURE AND TEMPERATURE ASSISTED BY TAGUCHI METHOD}

S u m m a r y

The injection molding process is one of the most efficient processes where mass production through automation is feasible and products with complex geometry at low cost are easily attained. In this study, an experimental work is performed on the effect of injection molding parameters on the polymer pressure and temperature inside the mold cavity. Different process parameters of the injection molding are considered during the experimental work including packing pressure, packing time, injection pressure, mold temperature, and melt temperature. The cavity pressure is measured with time by using Kistler pressure sensor at different injection molding cycles. The results show the packing pressure is significant factor of affecting the maximum of diverse spline cavity pressure. The mold temperature is significant factor of affecting the maximum cavity temperature. The results obtained specify well the developing of the cavity pressure and temperature inside the mold cavity during the injection molding cycles.

Keywords: micro-injection molding, cavity pressure, cavity temperature, process parameters, Taguchi design.

Received July 05, 2018

Accepted August 26, 2019 